\title{
Does azithromycin given to women in labour decrease ocular bacterial infection in neonates? A double-blind, randomized trial
}

\author{
Sarah E. Burr ${ }^{1}$, Bully Camara², Claire Oluwalana², Ebrima Bojang ${ }^{2}$, Christian Bottomley ${ }^{1}$, Abdoulie Bojang²,
} Robin L. Bailey', Umberto D'Alessandro ${ }^{1,2}$ and Anna Roca ${ }^{1,2^{*}}$

\begin{abstract}
Background: Vertical transmission can result in neonatal infection and disease. Reducing the transmission of bacterial pathogens from mother to infant may be an effective means of preventing neonatal infection, including bacterial conjunctivitis.

Methods: In a double-blind, randomized trial, we assessed the effect of administering a single dose of oral azithromycin to women in labour on bacterial colonization of the neonate. A reduction in purulent neonatal conjunctivitis was a secondary objective of the trial. Ocular samples were collected from the lower fornix of infants presenting with clinical signs of purulent conjunctivitis during the first eight weeks of life. Incidence of purulent conjunctivitis was compared between trial arms. Bacterial infection was assessed using PCR and incidence of purulent conjunctivitis due to bacteria was also compared between arms.
\end{abstract}

Results: Forty of 843 infants (4.7\%) presented clinical signs of purulent conjunctivitis. No significant difference in incidence of purulent conjunctivitis was seen between azithromycin and placebo arms [4.3\% (18/419) versus 5.2\% (22/424), OR=0.82, $95 \% \mathrm{Cl}(0.44,1.54), p=0.628]$. S. aureus was the most commonly identified pathogen, detected in $38 \%$ of cases. Incidence of purulent-conjunctivitis due to bacterial infection was lower in the azithromycin arm [1.2\% (5/419) versus 3.8\% $(16 / 424), \mathrm{OR}=0.31,95 \% \mathrm{Cl}(0.12-0.82), p=0.025)]$. The incidence of gram-positive bacteria was also lower in the azithromycin arm [1.0\% (4/419) versus 3.3\% (14/424), OR=0.28, 95\%Cl $(0.10-0.82), p=0.029]$.

Conclusions: Oral azithromycin given to women during labour may have the potential to reduce the incidence of bacterial neonatal conjunctivitis.

Trial registration: ClinicalTrials.gov, identifier NCT01800942, registration date 26 Feb 2013.

Keywords: Azithromycin, Randomized trial, Neonate, Conjunctivitis, Labour

\section{Background}

Ocular bacterial infection in neonates often results from vertical transmission, from mother to child, during delivery. The most common causes are Neisseria gonorrhoeae and Chlamydia trachomatis, although infection can also be attributed to other bacteria, including Staphylococcus aureus. Prenatal screening and treatment of expectant mothers is an effective means of preventing neonatal infection [1, 2]. Because bacterial conjunctivitis can give rise to complications including corneal ulceration,

\footnotetext{
* Correspondence: aroca@mrc.gm

'London School of Hygiene and Tropical Medicine, London, UK

${ }^{2}$ Medical Research Council Unit, The Gambia, Fajara, Banjul, The Gambia
}

perforation of the globe and visual impairment, many countries also recommend the use of ocular antibiotic ointment at birth as a preventive measure [3].

Vertical transmission during delivery can also result in invasive disease, including neonatal sepsis, which is an important cause of death in this age group [4]. S. aureus and Streptococcus pneumoniae are the most common cause of sepsis in African infants [5]. As asymptomatic carriage precedes bacterial invasion, interventions aimed at reducing carriage may provide an effective means of preventing disease. As an example, prenatal screening for group B streptococcus and the administration of intravenous antibiotics during labour have greatly 
reduced colonization and invasive neonatal disease in North American and Europe [6, 7]. However, this approach is not feasible in many low-income settings where simpler and more cost effective solutions for preventing neonatal sepsis are urgently needed. In The Gambia, West Africa, a recent randomized, double-blind trial (PregnAnZI) was conducted in which women were randomized to receive azithromycin or placebo during labour $[8,9]$. Azithromycin was chosen because it can be given orally, has significant effects with a single dose and does not require transport and storage in a cold chain. The aim of the trial was to reduce maternal carriage of $S$. aureus, $S$. pneumoniae and group B streptococcus during delivery thereby preventing vertical transmission and subsequent colonization of the neonates.

Trial results indicated a significant reduction in the carriage of all study bacteria in the vaginal swabs, breast milk and nasopharyngeal samples of mothers in the azithromycin arm as compared to the placebo arm during the first four weeks following delivery. As hypothesised, bacterial carriage was also reduced in the nasopharynx of neonates whose mothers received the intervention compared to those who received placebo; this reduction was maintained throughout the first month of life [9]. A reduction in disease was also documented in mothers who received azithromycin and in their neonates indicating a clinical benefit of treatment [10].

A secondary objective of the PregnAnZI trial was to assess the effect of giving azithromycin during labour on purulent neonatal conjunctivitis. Herein, we report the incidence of purulent conjunctivitis and purulent conjunctivitis associated with bacterial infection in the trial and its aetiology. We also report a risk factors analysis for bacterial conjunctivitis among study participants.

\section{Methods}

\section{Study design}

This was a phase III, double-blind, placebo controlled, randomized trial. The trial protocol and results of the primary endpoints have already been published $[8,9]$. Briefly, 829 women attending the study health facility during labour and who had previously given informed consent were randomized to receive an oral dose of $2 \mathrm{~g}$ of azithromycin or placebo. Mothers and their neonates were sampled throughout the first four weeks following delivery to determine the effect of treatment on vaginal, nasopharyngeal and breast milk carriage of $S$. pneumoniae, S. aureus and group B streptococcus. The primary trial end-point was nasopharyngeal carriage of the study bacteria in the neonate, at day six following delivery. As part of standard care in the country, newborns received tetracycline ointment in the eyes before hospital discharge. Active and passive follow-up was conducted for eight weeks after delivery.

\section{Sample collection}

An ocular swab was collected from infants presenting with purulent conjunctivitis during the first eight weeks of life. Samples were collected from the lower fornix using a sterile cotton swab and kept on wet ice at the clinic. All samples were transported to the laboratory within $8 \mathrm{~h}$ of collection for storage at $-70{ }^{\circ} \mathrm{C}$ until further processing.

\section{DNA extraction and PCR}

DNA was extracted using the QIAamp DNA Mini Kit (QIAGEN, Germany). The presence of DNA from $S$. pneumoniae, S. aureus, Moraxella catarrhalis, Haemophilus influenzae, C. trachomatis and $N$. gonorrhoeae was assayed using the FTD SPn/Staph/MC/Hi and Vaginal Swab kits (Fast-track Diagnostics, Luxembourg) run on a RotorGene 6000 real-time PCR cycler (QIAGEN, Germany). Samples were further tested for the presence of C. trachomatis DNA using droplet-digital PCR according to a previously published method [11]. Laboratory staff was blinded to allocation arm.

\section{Outcomes}

Pre-defined, secondary endpoints of the PregnAnZI trial included the proportion of newborns with at least one episode of purulent conjunctivitis and ocular C. trachomatis infection within the first week of life, the first four weeks of life and during the eight weeks of the follow-up period [8]. Purulent conjunctivitis caused by bacterial pathogens other than C. trachomatis was not a stated outcome of the trial and was investigated ad hoc.

\section{Statistical analysis}

Incidence of purulent conjunctivitis and purulent conjunctivitis due to defined bacterial pathogens was compared between arms. Due to the small numbers of cases seen, only the endpoint at eight weeks follow-up was considered, rather than assessing the three individual time-points specified in the original protocol [8]. Odds ratios and exact $p$-values for these comparisons were calculated using the cs command in Stata. Risk factors for bacterial conjunctivitis were analysed using data from both trial arms combined and from the control arm only.

\section{Ethical review}

The trial was approved by the Joint Gambian Government/ Medical Research Council Ethics Committee. An independent Data Safety Monitoring Board monitored the data quality and treatment safety. Written, informed consent was obtained from all women during visits to the antenatal clinic. 


\section{Results and discussion} Study participants

A total of 829 mothers and their offspring were recruited. Baseline characteristics were similar between intervention and control arms (Table 1).

\section{Incidence of purulent conjunctivitis}

Eight-hundred-forty-three babies were delivered including 13 stillbirths. Forty infants $(4.7 \%, 40 / 843)$ presented with purulent conjunctivitis during the eight-week follow-up period. Three infants were sampled on two separate occasions ( 1 in the azithromycin and 2 in the placebo arm). The median age at the onset of conjunctivitis was 4 days (IQR 2 to 8). Age of onset was missing for 6 cases of conjunctivitis. The median duration of clinical signs was 7 days (IQR 4 to 9). No difference was seen in the numbers of infants presenting with purulent conjunctivitis in the azithromycin $(4.3 \%, 18$ / $419)$ versus placebo $(5.2 \%, 22 / 424)$ arm $[\mathrm{OR}=0.82$, 95\%CI (0.44-1.54), $p=0.628$ ] (Table 2).

\section{Aetiology}

$S$. aureus was the most common bacteria, being identified in $38 \%(16 / 42)$ of the swabs tested (Table 2); one sample was missing in the laboratory analysis. This finding is consistent with the results of other studies in West Africa (Togo and Nigeria) that have reported $S$. aureus is a leading cause of bacterial neonatal conjunctivitis in this region $[12,13]$. No significant difference was seen in the incidence of $S$. aureus infection between trial arms with an overall incidence of $1.0 \%(4 / 419)$ in the azithromycin and $2.8 \%(12 / 424)$ in the placebo arm $[\mathrm{OR}=0.33$, 95\%CI $(0.11-0.98), p=0.074]$.

The incidence of infection with $S$. pneumoniae, $M$. catarrhalis, $H$. influenzae and $N$. gonorrhoeae was low. Although positive results for $S$. pneumoniae, $M$. catarrhalis and $H$. influenzae were only obtained in the placebo arm, no statistically significant difference was seen between trial arms, possibly because of the low numbers of infections detected. No sample was positive for $C$. trachomatis. While there is no recent data on urogenital C. trachomatis infection in The Gambia, our results are in keeping with historical data that indicates prevalence of infection is low $[14,15]$. Four swabs, all in the placebo arm, showed evidence of infection with more than one bacterium; 3 co-infected with 2 bacteria and 1 with 3 bacteria. All 3 samples positive for $H$. influenzae were co-infected with another bacteria (S. aureus; $S$. pneumoniae and M. catarrhalis; S. pneumoniae).

Table 1 Baseline characteristics of study participants

\begin{tabular}{|c|c|c|c|}
\hline Mothers & & Azithromycin arm $(N=414)$ & Placebo arm $(N=415)$ \\
\hline Characteristics & & $n(\%)$ & $n(\%)$ \\
\hline Age & (Median, IQR) & $26.0(22.0,30.0)$ & $25.0(22.0,30.0)$ \\
\hline \multirow[t]{4}{*}{ Ethnicity } & Madinka & $161(40.1)$ & $187(45.8)$ \\
\hline & Fula & $77(19.2)$ & $64(15.7)$ \\
\hline & Jola & $68(17.0)$ & $56(13.7)$ \\
\hline & Other & $95(23.7)$ & $101(24.8)$ \\
\hline Season of delivery ${ }^{a}$ & Rainy & $141(34.1)$ & $143(34.5)$ \\
\hline \multirow[t]{2}{*}{ Mode of delivery } & Vaginal & $404(97.6)$ & $410(98.8)$ \\
\hline & Caesarean & $10(2.4)$ & $5(1.2)$ \\
\hline Multiple pregnancy & Yes & $5(1.2)$ & $9(2.2)$ \\
\hline Hours from rupture of membrane to delivery ${ }^{b}$ & (Median, IQR) & $0.4(0.1,1.8)$ & $0.3(0.1,1.3)$ \\
\hline Newborns & & Azithromycin arm $(N=419)$ & Placebo arm $(N=424)$ \\
\hline Characteristics & & $n(\%)$ & $n(\%)$ \\
\hline Gender & Female & $207(49.4)$ & $198(46.7)$ \\
\hline \multirow[t]{2}{*}{ Apgar score at birth } & $0-6$ & $14(3.3)$ & $11(2.6)$ \\
\hline & $7-10$ & $402(96.6)$ & $408(97.4)$ \\
\hline Weight $^{\mathrm{c}}$ & (Median, IQR) & $3.1(2.8,3.5)$ & $3.1(2.9,3.4)$ \\
\hline \multicolumn{4}{|l|}{ Outcomes } \\
\hline Stillbirths & & $7(1.7)$ & $6(1.4)$ \\
\hline Deaths during the follow up period & & $8(1.9)$ & $8(1.9)$ \\
\hline
\end{tabular}

${ }^{\mathrm{a}}$ Rainy season: children born June to October

${ }^{\mathrm{b}}$ Time of rupture of membranes is missing in $n=441$ (230 in the azithromycin and 211 in the placebo arm)

'Weight missing in $n=2$ (both in the placebo arm) 
Table 2 Incidence of bacterial conjunctivitis reported by trial arm

\begin{tabular}{|c|c|c|c|c|}
\hline Characteristic & Azithromycin arm $(N=419) n(\%)$ & Placebo arm $(N=424) n(\%)$ & OR $(95 \% \mathrm{Cl})$ & $p$-value \\
\hline Purulent discharge & $18(4.3)$ & $22(5.2)$ & $0.82(0.44,1.54)$ & 0.628 \\
\hline Any bacteria detected & $5(1.2)$ & $16(3.8)$ & $0.31(0.12,0.82)$ & 0.025 \\
\hline Any gram-positive & $4(1.0)$ & $14(3.3)$ & $0.28(0.10,0.82)$ & 0.029 \\
\hline S. aureus & $4(1.0)$ & $12(2.8)$ & $0.33(0.11,0.98)$ & 0.074 \\
\hline S. pneumoniae & $0(0.0)$ & $2(0.5)$ & $0.00(0.00,1.94)$ & 0.499 \\
\hline Any gram-negative & $1(0.2)$ & $6(1.4)$ & $0.17(0.00,1.06)$ & 0.123 \\
\hline H. influenzae & $0(0.0)$ & $3(0.7)$ & $0.00(0.00,1.29)$ & 0.249 \\
\hline M. catarrhalis & $0(0.0)$ & $3(0.7)$ & $0.00(0.00,1.29)$ & 0.249 \\
\hline N. gonorrhoeae & $1(0.2)$ & $1(0.2)$ & $1.01(0.00, N A)$ & 1.00 \\
\hline C. trachomatis & $0(0.0)$ & $0(0.0)$ & - & - \\
\hline Bacterial co-infection $^{\mathrm{a}}$ & $0(0.0)$ & $4(0.9)$ & $0.00(0.00,0.97)$ & 0.124 \\
\hline
\end{tabular}

${ }^{a}$ Bacterial co-infections: (i) S. aureus and H. influenzae; (ii) S. pneumoniae and H. influenzae; (iii) S. aureus and N. gonohorreae (iv) M. catarrhalis, S. pneumoniae and H. influenzae

Overall, the incidence of purulent bacterial conjunctivitis was lower in the azithromycin arm $[1.2 \%(5 / 419)$ versus $3.8 \%(16 / 424)$, OR $=0.31,95 \%$ CI $(0.12-0.82), p=0.025)]$ suggesting a beneficial effect of treatment. The incidence of conjunctivitis associated with gram-positive bacteria was also lower in the intervention arm [1.0\% (4/419) versus $3.3 \%$ (14/424), OR $=0.28,95 \% \mathrm{CI}(0.10-0.82), p=0.029$ ] (Table 2). The incidence of gram-negative bacteria was lower in the intervention arm however this difference was not statistically significant $[0.2 \%(1 / 419)$ versus $1.4 \%$ (6/ $424), \mathrm{OR}=0.17,95 \% \mathrm{CI}(0.00-1.06), p=0.123]$.

\section{Risk factors}

Vaginal colonization of the mother with any of the trial study bacteria (S. aureus, S. pneumoniae and group B streptococcus) prior to azithromycin administration was not a risk factor for ocular infection in the neonate (both trial arms, $\mathrm{OR}=1.36,95 \% \mathrm{CI} 0.54-3.41, p=0.468$; placebo arm only, $\mathrm{OR}=1.51,95 \% \mathrm{CI}$ 0.54-4.25, $p=0.412$ ) (Table 3). These findings however are limited as our analysis of ocular swabs targeted more pathogens than the three study bacteria that were analysed in the vaginal swabs. Recto-vaginal swabs from mothers may also have yielded a better comparison than vaginal swabs alone.

Differences in risk of neonatal bacterial conjunctivitis were not significant among infants who received tetracycline ointment in the eye at birth compared to those who did not although odds ratios were lower for those who received ointment (both trial arms, OR $=0.79,95 \% \mathrm{CI}$ $0.23-2.75, p=0.728$; placebo arm only, $\mathrm{OR}=0.52,95 \% \mathrm{CI}$ 0.14-1.91, $p=0.404$ ) (Table 3). While other topical antimicrobial agents are available for use in neonates, evidence suggests that prophylaxis with tetracycline ointment does result in better outcomes in comparison to others such as povidone-iodine or erythromycin [16, 17]. Premature rupture of the membranes, which is a risk factor for conjunctivitis in the low-income setting of Malawi [18], was not a risk factor in The Gambia (both trial arms, OR = 1.12 , 95\%CI $0.47-2.68, p=0.829$; placebo arm only, $\mathrm{OR}=$ $1.59,95 \%$ CI $0.57-4.45, p=0.450$ ) (Table 3).

\section{Limitations}

The majority of infants in the trial received ocular tetracycline ointment after delivery, as is standard care in The Gambia. This may have lowered incidence of infection or modified the distribution of pathogens thereby impacting our endpoint. Our study is also limited by statistical power, as the trial was not designed to detect differences in the incidence of conjunctivitis or bacterial conjunctivitis between study arms. While the results showed a trend of lower incidence in the azithromycin arm for almost all bacteria assayed, significant results were obtained only when grouping all purulent bacterial conjunctivitis and conjunctivitis associated with gram-positive bacteria. The majority of samples collected from the azithromycin arm were negative for all the bacteria assayed suggesting conjunctivitis in these infants may have been chemical or viral in nature. However, our panel focused only on the major causes of bacterial conjunctivitis in neonates. It is possible that some cases could have been due to less common bacteria, yet there is no reason to believe that any other bacteria would have been more prevalent in the azithromycin arm. The limited power also extends to the risk factor analysis and may explain why tetracycline ointment or the premature rupture of membranes were not associated with conjunctivitis.

Ocular swabs were collected in the absence of transport media for the detection of $C$. trachomatis DNA by molecular means, as purulent conjunctivitis with $C$. trachomatis infection was a pre-specified outcome of the trial. This prevented us from evaluating other bacterial 
Table 3 Risk factors for neonatal bacterial eye infection

\begin{tabular}{|c|c|c|c|c|c|c|c|c|}
\hline \multirow[t]{2}{*}{ Characteristic } & \multicolumn{4}{|c|}{ Both trial arms } & \multicolumn{4}{|c|}{ Placebo arm only } \\
\hline & $\mathrm{N}$ & $n(\%)$ & OR $(95 \% \mathrm{Cl})$ & $p$-value & N & $n(\%)$ & OR $(95 \% \mathrm{Cl})$ & $p$-value \\
\hline \multicolumn{9}{|c|}{$>18 \mathrm{~h}$ membrane rupture to birth } \\
\hline No & 384 & 2.3 & 1 & & 205 & 2.9 & 1 & \\
\hline Yes & 459 & 2.6 & $1.12(0.47,2.68)$ & 0.829 & 219 & 4.6 & $1.59(0.57,4.45)$ & 0.45 \\
\hline \multicolumn{9}{|l|}{ Gender } \\
\hline Female & 405 & 1.7 & 1 & & 198 & 2.5 & 1 & \\
\hline Male & 438 & 3.2 & $1.88(0.75,4.70)$ & 0.191 & 226 & 4.9 & $1.97(0.67,5.79)$ & 0.307 \\
\hline \multicolumn{9}{|l|}{ Apgar score } \\
\hline 0 & 12 & 0.0 & NA & & 6 & 0.0 & NA & \\
\hline $1-6$ & 13 & 0.0 & NA & & 5 & 0.0 & NA & \\
\hline $7-10$ & 810 & 2.6 & NA & 1 & 408 & 3.9 & NA & 1 \\
\hline \multicolumn{9}{|c|}{ Low birth-weight (<2.5 kg) } \\
\hline No & 786 & 2.5 & 1 & & 392 & 3.8 & 1 & \\
\hline Yes & 55 & 1.8 & $0.71(0.09,5.39)$ & 1 & 30 & 3.3 & $0.87(0.11,6.79)$ & 1 \\
\hline \multicolumn{9}{|c|}{ Bacteria in the vaginal swab prior to intervention } \\
\hline No & 615 & 2.3 & 1 & & 302 & 3.3 & 1 & \\
\hline Yes & 228 & 3.1 & $1.36(0.54,3.41)$ & 0.468 & 122 & 4.9 & $1.51(0.54,4.25)$ & 0.412 \\
\hline \multicolumn{9}{|l|}{ Season } \\
\hline Dry & 557 & 2.0 & 1 & & 280 & 2.9 & 1 & \\
\hline Wet & 286 & 3.5 & $1.80(0.75,4.29)$ & 0.242 & 144 & 5.6 & $2.00(0.73,5.44)$ & 0.184 \\
\hline \multicolumn{9}{|c|}{ Tetracycline at birth } \\
\hline No & 99 & 3.0 & 1 & & 47 & 6.4 & 1 & \\
\hline Yes & 743 & 2.4 & $0.79(0.23,2.75)$ & 0.728 & 377 & 3.4 & $0.52(0.14,1.91)$ & 0.404 \\
\hline \multicolumn{9}{|c|}{ Mothers' years of schooling } \\
\hline$<1$ year & 424 & 2.6 & 1 & & 210 & 3.8 & 1 & \\
\hline $1+$ years & 398 & 2.5 & $0.97(0.41,2.30)$ & 1 & 203 & 3.9 & $1.04(0.38,2.81)$ & 1 \\
\hline \multicolumn{9}{|l|}{ Ethnicity } \\
\hline Madinka & 352 & 2.3 & 1 & & 189 & 3.7 & 1 & 0.691 \\
\hline Wollof & 94 & 1.1 & $0.46(0.06,3.74)$ & & 47 & 2.1 & $0.57(0.07,4.71)$ & 0.691 \\
\hline Jola & 127 & 5.5 & $2.51(0.89,7.06)$ & & 59 & 6.8 & $1.89(0.53,6.70)$ & 0.691 \\
\hline Fula & 144 & 2.8 & $1.23(0.36,4.15)$ & & 66 & 4.5 & $1.24(0.31,4.93)$ & 0.691 \\
\hline Other & 106 & 0.9 & $0.41(0.05,3.31)$ & 0.23 & 56 & 1.8 & $0.47(0.06,3.93)$ & 0.691 \\
\hline
\end{tabular}

infection by routine culture. However, PCR is generally considered more sensitive than conventional bacteriological techniques so we do not anticipate this adversely impacted our results.

\section{Conclusions}

While numbers were small, our data suggest azithromycin given in labour may provide a means of decreasing the risk of ocular bacterial infection in the neonate. Larger scale trials to determine the impact of azithromycin treatment in labour on neonatal sepsis are currently underway. If these studies show a benefit, there may be a case for recommending this intervention for deliveries as a means of decreasing neonatal mortality.

Abbreviations

PregnAnZl: Prevention of bacterial infections in newborn trial

\section{Acknowledgements}

We thank the mothers and their newborns who participated in our study. We are especially grateful to the study field team, the Clinical Trials Office, our internal monitor (Vivat Thomas), the local safety monitor (Aderonke Odutola) and the Data Safety Monitoring Board team chaired by Daniel Chandramohan, with Brian Greenwood, Maria Quigley, Stephen Howie and Hannah Blencowe. 


\section{Funding}

This trial was jointly supported by the UK MRC and the UK Department for International Development (DFID) under the MRC/DFID Concordat agreement [reference number MR/.

J010391/1] and is also part of the EDCTP2 programme supported by the European Union. The MRC Unit in The Gambia receives core funding from the MRC UK. The funders had no role in the study design, data collection, analysis and interpretation of the data, decision to publish, or preparation of the manuscript.

\section{Availability of data and materials}

The raw data supporting the findings of the study is available upon request following ethical approval by the local ethics committee. For any query Anna Roca, the corresponding author, can be contacted.

\section{Authors' contributions}

SEB carried out the laboratory work, interpreted the data and drafted the manuscript, BC was involved in sample collection, CO was involved in sample collection, EB assisted with the laboratory work and in writing the manuscript, CB carried out the statistical analysis and assisted in writing the manuscript, $A B$ assisted in data collection and in writing the manuscript, RLB was involved in study design and assisted in writing the manuscript, UDA was involved in study design and assisted in writing the manuscript, AR was involved in study design, project supervision, interpreting the data and drafting the manuscript. All authors read and approved the final manuscript.

\section{Ethics approval and consent to participate}

The trial was approved by the Joint Gambian Government/ Medical Research Council Ethics Committee. Written, informed consent was obtained from all participants.

\section{Consent for publication}

Not applicable.

\section{Competing interests}

The authors declare that they have no competing interests.

\section{Publisher's Note}

Springer Nature remains neutral with regard to jurisdictional claims in published maps and institutional affiliations.

Received: 31 March 2017 Accepted: 12 December 2017

Published online: 28 December 2017

\section{References}

1. Adachi K, Nielsen-Saines K, Klausner JD. Chlamydia trachomatis infection in pregnancy: the global challenge of preventing adverse pregnancy and infant outcomes in sub-Saharan Africa and Asia. Biomed Res Int. 2016;2016: 9315757.

2. Moore DL, MacDonald NE, Canadian Paediatric Society. Preventing ophthalmia neonatorum. Can J Infect Dis Med Microbiol. 2015;26:122-5.

3. Mallika P, Asok T, Faisal H, Aziz S, Tan A, Intan G. Neonatal conjunctivitis - a review. Malays Fam Physician. 2008:3:77-81.

4. Liu L, Oza S, Hogan D, Perin J, Rudan I, Lawn JE, Cousens S, Mathers C, Black RE. Global, regional, and national causes of child mortality in 2000-13, with projections to inform post-2015 priorities: an updated systematic analysis. Lancet. 2008;385:430-40.

5. Waters D, Jawad I, Ahmad A, Lukšić I, Nair H, Zgaga L, Theodoratou E, Rudan I, Zaidi AK, Campbell H. Aetiology of community-acquired neonatal sepsis in low and middle income countries. J Glob Health. 2011;1:154-70.

6. Verani JR, McGee L, Schrag SJ. Prevention of perinatal group B streptococcal disease: revised guidelines from CDC, 2010. MMWR. 2010;59:1-36.

7. Di Renzo GC, Melin P, Berardi A, Blennow M, Carbonell-Estraany X, Donzelli GP, Hakansson S, Hod M, Hughes R, Kurtzer M, Poyart C, Shinwell E, Stray-Pedersend B, Wielgos M, El Helali N. Intrapartum GBS screening and antibiotic prophylaxis: a European consensus conference. J Matern Fetal Neonatal Med. 2015;28:766-82.

8. Roca A, Oluwalana C, Camara B, Bojang A, Burr S, Davis TM, Bailey R, Kampmann B, Mueller J, Bottomley C, D'Alessandro U. Prevention of bacterial infections in the newborn by pre-delivery administration of azithromycin: study protocol of a randomized efficacy trial. BMC Pregnancy Childbirth. 2015;15:302.

9. Roca A, Oluwalana C, Bojang A, Camara B, Kampmann B, Bailey R, Demba A, Bottomley C, D'Alessandro U. Oral azithromycin given during labour decreases bacterial carriage in the mothers and their offspring: a double-blind randomized trial. Clin Microbiol Infect. 2016;22:565. e1-e9

10. Oluwalana C, Camara B, Bottomley C, Goodier S, Bojang A, Kampmann B, Ceesay S, D'Alessandro U, Roca A. Azithromycin in labor lowers clinical infections in mothers and newborns: a double-blind trial. Pediatrics. 2017; 139:e20162281.

11. Roberts CH, Last A, Molina-Gonzalez S, Cassama E, Butcher R, Nabicassa M McCarthy E, Burr SE, Mabey DC, Bailey RL, Holland MJ. Development and evaluation of a next-generation digital PCR diagnostic assay for ocular Chlamydia trachomatis infections. J Clin Microbiol. 2013;51:2195-203.

12. Ayena KD, Amedome KM, Diallo JW, Dzidzinyo KB, Azoumah KD, Aboubakari AS, Salou M, Koffi SK, Tchassi N, Balo KP. [what remains today of neonatal conjunctivitis in prefecture of Kozah in Togo?] French. J Fr Ophtalmol. 2012;35:432-6.

13. Olatunji FO, Fadeyi A, Ayanniyi AA, Akanbi AA 2nd. Non-gonococcal bacterial agents of conjunctivitis and their antibiotic susceptibility patterns in Llorin, Nigeria. Afr J Med Med Sci. 2007;36:243-7.

14. Mabey DCW, Whittle HC. Genital and neonatal chlamydial infection in a trachoma endemic area. Lancet. 1982;320:300-1.

15. Walraven G, Scherf C, West B, Ekpo G, Paine K, Coleman R, Bailey R, Morison $\mathrm{L}$. The burden of reproductive-organ disease in rural women in the Gambia, West Africa. Lancet. 2001:357:1161-7.

16. Matejcek A, Goldman RD. Treatment and prevention of opthalmia neonatorum. Can Fam Physician. 2013;59:1187-90.

17. Zuppa AA, D'Andrea V, Catenazzi P, Scorrano A, Romagnoli C. Opthalmia neonatorum: what kind of prophylaxis? J Matern Fetal Neonatal Med. 2011; 24:769-73.

18. Msukwa G, Batumba N, Drucker M, Menezes L, Ranjit R. Maternal and neonatal risk factors associated with vertical transmission of ophthalmia neonatorum in neonates receiving health care in Blantyre, Malawi. Middle East Afr J Ophthalmol. 2014;21:240-3.

\section{Submit your next manuscript to BioMed Central and we will help you at every step:}

- We accept pre-submission inquiries

- Our selector tool helps you to find the most relevant journal

- We provide round the clock customer support

- Convenient online submission

- Thorough peer review

- Inclusion in PubMed and all major indexing services

- Maximum visibility for your research

Submit your manuscript at www.biomedcentral.com/submit
) Biomed Central 